\title{
Prevalence, Knowledge, Attitude and Practices of Diabetes Mellitus among Jazan Population, Kingdom of Saudi Arabia (KSA)
}

\author{
Ibrahim A. Bani \\ Department of Family and Community Medicine, Faculty of Medicine, Jazan University, Jizan, KSA \\ Email: bani1984@gmail.com
}

Received 2 April 2015; accepted 16 May 2015; published 19 May 2015

Copyright (C) 2015 by author and Scientific Research Publishing Inc.

This work is licensed under the Creative Commons Attribution International License (CC BY). http://creativecommons.org/licenses/by/4.0/

(c) (i) Open Access

\begin{abstract}
Background: Diabetes mellitus (DM) prevalence is increasing in Arabian Gulf countries and Saudi Arabia is ranked as the 7th country world widely estimated to have the highest numbers of people with diabetes in $\mathbf{2 0 0 0}$ and 2030. Objectives: This study intended to estimate the prevalence, risk factors of diabetes among adult population of Jazan region, Saudi Arabia. Methods: Observational cross sectional survey conducted among adult Saudi population aged 15 years of age and over who attended eight Primary Health Care Centers (PHCCs) in Jazan region. Standardized questionnaire as well as diabetic registry was utilized for this research. The questionnaire involved risk factors of DM and socio-demographic variables. Statistical analysis involved: chi-square test (or Fisher exact test where applicable) was used to evaluate the prevalence of DM among different subgroups. The crude odds ratios (OR) were estimated by univariate analysis to observe the association of each variable with DM. Results: The overall prevalence of DM among study participants was found to be $12.3 \%$ (95\% CI: 10.9 - 13.8). The prevalence of DM according to gender showed that women are of significantly higher prevalence $19.0 \%$ with confidence interval (95\% C.I. 15.9 - 22.6), compared with only $9.8 \%$ for male (95\% CI. 8.4 - 11.4). Participant's body mass index, age, family history of diabetes and daily exercise and work involved physical activities that showed a significant association with DM. Conclusion: Increased prevalence of diabetes calls for urgent steps towards prevention and health promotion, programs designed to reduce its burden.
\end{abstract}

\section{Keywords}

Diabetes, Saudi Arabia, Prevalence, Risk-Factors and BMI

\section{Introduction}

Diabetes mellitus (DM) is considered as one of the most chronic diseases that faced humankind. It affected human

How to cite this paper: Bani, I.A. (2015) Prevalence, Knowledge, Attitude and Practices of Diabetes Mellitus among Jazan Population, Kingdom of Saudi Arabia (KSA). Journal of Diabetes Mellitus, 5, 115-122. 
kind and continued to do so, but in steady increasing rate. Globally the burden of Diabetes mellitus is overwhelming. It is estimated that the total number of people with diabetes is to reach 221 million in 2010 and this number will increase to 366 million in 2030 [1] [2].

Kingdom of Saudi Arabia had achieved a notable economic growth and improvement in life quality. The country enjoys high level of economic growth and development during the past three decades. The population of country had experienced remarkable change in life styles and hence increasing rate of non-communicable disease [3]-[6]. Saudi Arabia is considered as the seventh highest rate in the world in terms of diabetes incidence, with about 3.4 million people having been diagnosed with diabetes. The recent estimate of the disease showed that $24.4 \%$ of the adult population is suffering from DM.

A review of literature indicates that proper education and awareness program can improve the knowledge of patients and change their attitude as a large gap was found between knowledge and attitude [2] [4].

Obtaining information about the prevalence, risk factors of DM is the first step in formulating a preventive program for the disease. Also there is increasing need to investigate KAP among diabetic patients to help in future development of programs and techniques for effective health education [7].

The objectives of this study were to determine the prevalence of diabetes mellitus and its associated factors among population of Jazan region south west of KSA and to investigate their knowledge attitude and practices towards this disease.

\section{Material and Methods}

\subsection{Study Design and Population}

Observational cross sectional survey conducted among adult Saudi population aged 15 years of age and over who attended eight Primary Health Care Centers (PHCCs) in Jazan region, Saudi Arabia during November, 2006. The sample size was calculated depending on the prevalence of DM in KSA, giving a sample of 2200 participants. The sample design was cluster random sampling based on primary health centers covering Jazan region. Eight PHCCs were selected at random and subjects were selected using systemic random sample from each PHCC attendance list.

\subsection{Data Collection}

The data was collected by 4th Year Medical Students during their field training course. The students used a questionnaire that included demographic data, smoking and Qat consumption, blood pressure measurement, anthropometric data, physical activity, dietary habits and knowledge attitude and practice towards DM. Each subject was interviewed for 20 - 30 minutes. Students were trained for data collection before commencement of the survey.

Height and weight were measured using standardized methods and Body Mass Index (BMI) calculated using chart of the National Heart, Lung, and Blood Institute (NIH) USA. Blood pressure measurement was carried out by trained medical students according to World Health Organization (WHO) standardized criteria. DM data were checked using the DM registry at the Non-communicable disease (NCD) clinic of the PHCC. The collected data was cleaned and entered over a week, and potential errors were identified and corrective actions taken.

\subsection{Data Management Analysis}

The data entry and analysis were performed using Statistical Package for the Social Sciences Program (SPSS) 17th Edition. The overall prevalence of DM among patients was calculated with a 95\% confidence interval (CI). The chi-square test (or Fisher exact test where applicable) was used to evaluate the prevalence of DM among different sub-groups. The crude odds ratios (OR) were estimated by univariate analysis to observe the association of each variable with DM. All statistical tests were two-sided; and a level of $\mathrm{P}<0.05$ was used to indicate statistical significance.

\subsection{Ethical Consideration}

Ethical approval was obtained from the Medical Research Ethics Committee of Faculty of Medicine. Participation was voluntary and verbal consent was acquired from all participants. Confidentiality of all participants was 
maintained as no names were mentioned in the questionnaires, participant were told that they have the complete free dome to quit the study at any time.

\section{Results}

Two thousands and twenty three (2023) persons were met the inclusion criteria and participated in the study (586 women and 1487 men) the response rate was estimated at 92\%. Males constituted a large number of the sample $73.5 \%$ in comparison to $26.4 \%$ for females participants (Table 1). The distribution of study subjects according to age shows that $65.9 \%$ are in the age group (15 - 39) years, $69.7 \%, 55.4 \%$ for male and female respectively.

Table 1. Some selected characteristics of Study participants.

\begin{tabular}{|c|c|c|c|}
\hline Characteristics & Male N\% & Female N\% & Total N\% \\
\hline \multicolumn{4}{|l|}{ Age Groups } \\
\hline $15-39$ & $1036(69.7)$ & $297(55.4)$ & $1333(65.9)$ \\
\hline $40-49$ & $188(12.6)$ & $107(20.0)$ & $295(14.6)$ \\
\hline $50-59$ & $148(10.0)$ & $67(12.5)$ & $215(10.6)$ \\
\hline $60+$ & $115(7.7)$ & $65(12.1)$ & $180(8.9)$ \\
\hline \multicolumn{4}{|l|}{ Education } \\
\hline Illiterate & $155(10.4)$ & $233(43.5)$ & $388(19.2)$ \\
\hline Incomplete schooling & $81(5.4)$ & $34(6.3)$ & $115(5.7)$ \\
\hline Completed Primary School & $157(10.6)$ & $42(7.8)$ & $199(9.8)$ \\
\hline Completed Intermediate School & $324(21.8)$ & $43(8.0)$ & $367(18.1)$ \\
\hline Completed secondary School & 400 (26.9) & $91(17.0)$ & $491(24.2)$ \\
\hline University and above & $360(24.8)$ & $93(17.6)$ & 463 (22.9) \\
\hline \multicolumn{4}{|l|}{ Marital Status } \\
\hline Single & $708(47.6)$ & $102(19.0)$ & $810(40.0)$ \\
\hline Married & $731(49.2)$ & $370(69.0)$ & $1101(54.4)$ \\
\hline Married in Polygamy Relations & $44(3.0)$ & $5(.9)$ & $49(2.4)$ \\
\hline Divorced & $2(0.1)$ & $17(3.2)$ & $19(.9)$ \\
\hline Widowed & $2(0.1)$ & $42(7.8)$ & $44(2.2)$ \\
\hline \multicolumn{4}{|l|}{ Occupation } \\
\hline Government Employee & $599(40.3)$ & 89 (16.6) & $688(34.0)$ \\
\hline Private Sector Employee & $131(8.8)$ & $8(1.5)$ & 139 (6.9) \\
\hline Student & $487(32.8)$ & $54(10.1)$ & $541(26.7)$ \\
\hline House Wife & - & $327(61.0)$ & $336(16.6)$ \\
\hline Retired & $117(7.9)$ & $5(.9)$ & $122(6.0)$ \\
\hline Unemployed & $153(8.5)$ & 53 (9.9) & $197(9.7)$ \\
\hline \multicolumn{4}{|l|}{ Family Income $(n=1362)$} \\
\hline Less than $3000 \mathrm{SR}$ & $252(25.2)$ & $174(48.1)$ & $426(31.3)$ \\
\hline 3000 - 4999 SR & $215(21.5)$ & 43 (11.9) & $258(18.9)$ \\
\hline $5000-6999$ SR & $166(16.6)$ & $74(20.4)$ & $240(17.6)$ \\
\hline 7000 - 9999 SR & $163(16.3)$ & $37(10.2)$ & $200(14.7)$ \\
\hline 10000 and More SR & $204(20.4)$ & $34(9.4)$ & $238(17.5)$ \\
\hline
\end{tabular}


Illiterate people were $19.2 \%$, while those who completed secondary education were $24.2 \%$ participants. About $54.4 \%$ of study participants were married in single union compared with only $2.4 \%$ who were also married but in polygamy relation, while single participants were $40 \% .34 .0 \%$ are working in government institutions, compared with $18.9 \%$ in private sector. Regarding the income distribution almost $50 \%$ of respondents are with monthly family income less than 5000 SR.

The prevalence of DM according to some demographic and socio-economic characteristics is shown in Table 2. The prevalence of DM according to gender showed that women are of higher prevalence $19.0 \%$ with confidence interval (95\% C.I. 15.9 - 22.6), compared with only 9.8\% for male (95\% CI. 8.4 - 11.4). The age specific prevalence rate showed a general increase of DM with age with significant difference between the different age groups. The lowest prevalence were found among age group (15 - 39) years 3.6\% (95\% CI. 1.9 - 4.2), while the highest prevalence reported for the age group $60+40.6 \%$ (95\% CI. 33.6 - 47.9). The prevalence of DM according to marital status $50 \%$ of widowed respondents were diabetic patients (95\% CI 35.8 - 64.2), followed by divorced participants $31.6 \%$ and married $17.1 \%$. According to the occupational status, $25 \%$ house wife and retired

Table 2. Prevalence of diabetic mellitus according to some selected characteristics.

\begin{tabular}{|c|c|c|c|}
\hline Characteristics & N\% & 95\% C.I. & P Value \\
\hline \multicolumn{4}{|l|}{ Gender } \\
\hline Male & $146(9.8)$ & $8.4-11.4$ & \multirow[t]{2}{*}{0.000} \\
\hline Female & $102(19.0)$ & $15.9-22.6$ & \\
\hline \multicolumn{4}{|l|}{ Age Groups } \\
\hline $15-39$ & $48(3.6)$ & $2.7-4.7$ & \multirow{4}{*}{0.000} \\
\hline $40-49$ & $67(22.7)$ & $18.3-27.8$ & \\
\hline $50-59$ & $60(27.9)$ & $22.3-34.3$ & \\
\hline $60+$ & $73(40.6)$ & $33.6-47.9$ & \\
\hline \multicolumn{4}{|l|}{ Marital Status } \\
\hline Single & $23(2.8)$ & $1.9-4.2$ & \multirow{5}{*}{0.000} \\
\hline Married & $188(17.1)$ & $15-19.4$ & \\
\hline Married in Polygamy Relations & $9(18.4)$ & $10.0-31.4$ & \\
\hline Divorced & $6(31.6)$ & $15.4-5.42$ & \\
\hline Widowed & $22(50.0)$ & $35.8-64.2$ & \\
\hline \multicolumn{4}{|l|}{ Occupation } \\
\hline Government Employee & 89 (12.9) & $10.6-15.6$ & \multirow{6}{*}{0.000} \\
\hline Private Sector Employee & $20(14.4)$ & $10.5-21.2$ & \\
\hline Student & $10(1.8)$ & $1.0-3.3$ & \\
\hline House Wife & $84(25.0)$ & $20.5-29.7$ & \\
\hline Retired & 31 (25.4) & $18.5-33.8$ & \\
\hline Unemployed & $14(7.1)$ & $4.3-11.6$ & \\
\hline \multicolumn{4}{|l|}{ Family income $(n=1362)$} \\
\hline Less than $3000 \mathrm{SR}$ & $64(15.0)$ & $11.9-18.7$ & \multirow{6}{*}{0.005} \\
\hline 3000 - 4999 SR & $26(10.1)$ & $7.0-14.4$ & \\
\hline 5000 - 6999 SR & $13(5.4)$ & $3.2-9.0$ & \\
\hline 7000 - 9999 SR & $24(12.0)$ & $8.2-17.2$ & \\
\hline 10000 and More SR & 31 (13.0) & $9.3-17.9$ & \\
\hline Overall Prevalence & $248(12.3)$ & $10.9-13.8$ & \\
\hline
\end{tabular}


population were diabetic patient. 15\% of people with monthly income less than 3000 SR were diabetic patients (95\% CI. 11.9 - 18.7). The overall prevalence of DM among study participants was found to be $12.3 \%$ (95\% CI: 10.9 - 13.8). The table further suggested there is a significant difference between DM prevalence according to gender, marital status and between patients according to occupation and monthly family income.

Table 3 shows the prevalence of DM and its association with some selected risk factors. According to the table participant's body mass index, age, family history of diabetes and daily exercise and work involved physical activities showed a significant association with DM. Age greater than 40 years increases the risk of DM ten times while family history of DM increase the risk three times. Obesity increases the risk DM twice while doing daily exercise decreases the risk twice.

Majority of the DM patients in our study (96.0\%), 97.3\% male and 93.1\% females were aware about important of monitoring DM, with no significant difference between males and females (Table 4). About half of the DM patients are using oral hypoglycemic, while one quarter of them are using insulin with no significant difference between males and females. Dietary regimen, weight reduction and practice of exercise were accepted by less than half of studied patients (35.1\%, 34.7\%, 39.4\% respectively). Only $18.5 \%$ of DM patients opted to alternative medicine like plans and weeds to as a choice to treat DM (Table 4).

Table 3. Prevalence of DM and its association with some selected risk factor (OR and 95\% confidence intervals) among study participants.

\begin{tabular}{|c|c|c|c|c|}
\hline Characteristics & Diabetic & Non-Diabetic & OR $\quad(95 \% \mathrm{CI})$ & P Value \\
\hline \multicolumn{5}{|l|}{ General Obesity } \\
\hline $\mathrm{BMI}<30$ & $156(10.1)$ & 1391 (89.9) & 1 & 0.000 \\
\hline $\mathrm{BMI}>30$ & 86 (18.9) & 368 (81.1) & $2.08(1.5-2.7)$ & \\
\hline \multicolumn{5}{|l|}{ Age } \\
\hline Less than 40 & $48(3.6)$ & 1285 (96.4) & 1 & 0.000 \\
\hline Greater Than 40 & $200(29.0)$ & $490(71.0)$ & $10.9(7.8-15.2)$ & \\
\hline \multicolumn{5}{|c|}{ Family History of Diabetic } \\
\hline No & $86(7.1)$ & 1126 (92.9) & 1 & 0.000 \\
\hline Yes & $162(20.0)$ & $649(80.0)$ & $3.2(2.4-4.3)$ & \\
\hline \multicolumn{5}{|c|}{ Addiction to Khat } \\
\hline No & $180(13.0)$ & $1206(87.0)$ & 1 & 0.141 \\
\hline Yes & $68(10.7)$ & 569 (89.3) & $0.8(.50-1.1)$ & \\
\hline \multicolumn{5}{|c|}{ Addiction to Tobacco } \\
\hline No & 198 (13.3) & $1291(86.7)$ & 1 & 0.017 \\
\hline Yes & $50(9.4)$ & $484(90.6)$ & $0.6(0.4-0.9)$ & \\
\hline \multicolumn{5}{|l|}{ Hypertension } \\
\hline Absent & $151(9.8)$ & $1392(90.2)$ & 1 & 0.000 \\
\hline Present & 65 (35.7) & 117 (64.3) & $5.1(3.6-7.2)$ & \\
\hline \multicolumn{5}{|c|}{ Doing Exercise Daily } \\
\hline Yes & 63 (15.6) & 341 (84.4) & 1 & 0.000 \\
\hline No & $47(7.4)$ & $586(92.6)$ & $2.3(1.5-3.4)$ & \\
\hline \multicolumn{5}{|c|}{ Work involve Physical Activity } \\
\hline Yes & $92(15.0)$ & $523(85.0)$ & 1 & 0.016 \\
\hline No & $156(11.1)$ & $1246(88.9)$ & $1.4(1.1-1.8)$ & \\
\hline
\end{tabular}


Table 4. Knowledge, attitude \& practice of diabetic mellitus among patients about their disease.

\begin{tabular}{|c|c|c|c|c|c|}
\hline \multirow{2}{*}{ Category } & \multirow{2}{*}{ Characteristics } & Male & Female & Total & \multirow{2}{*}{ P Value } \\
\hline & & N\% & N\% & N\% & \\
\hline & Awareness & & & & \\
\hline \multirow[t]{9}{*}{ Knowledge } & Aware & 143 (97.9) & 95 (93.1) & $238(96.0)$ & 0.056 \\
\hline & Not Aware & $3(2.1)$ & $7(6.9)$ & $10(4.0)$ & \\
\hline & Oral Hypoglycemic & & & & \\
\hline & Yes & 95 (51.1) & $64(55.7)$ & $159(52.8)$ & 0.440 \\
\hline & No & $91(48.9)$ & $51(44.3)$ & $142(47.2)$ & \\
\hline & Dietary regimen & & & & \\
\hline & Yes & $90(27.7)$ & $84(49.1)$ & $174(35.1)$ & 0.040 \\
\hline & No & 235 (72.3) & 87 (50.9) & 322 (64.9) & \\
\hline & Insulin Treatment & & & & \\
\hline \multirow[t]{9}{*}{ Management } & Yes & 37 (20.3) & $42(36.5)$ & 79 (26.6) & 0.003 \\
\hline & No & 145 (79.7) & 73 (63.5) & $218(73.4)$ & \\
\hline & Weight reduction & & & & \\
\hline & Yes & 90 (31.5) & $58(41.1)$ & $148(34.7)$ & 0.048 \\
\hline & No & $196(68.5)$ & 83 (58.9) & $279(65.3)$ & \\
\hline & Practicing exercise & & & & \\
\hline & Yes & 108 (37.9) & $61(42.4)$ & 169 (39.4) & 0.371 \\
\hline & No & 177 (62.1) & $83(57.6)$ & $260(60.6)$ & \\
\hline & $\begin{array}{c}\text { Alternative medicine } \\
\text { (e.g. Medicinal plants) to treat DM }\end{array}$ & & & & \\
\hline \multirow[t]{2}{*}{ Attitude } & Yes & $26(11.9)$ & 37 (30.3) & $63(18.5)$ & 0.000 \\
\hline & No & 193 (88.1) & 85 (69.7) & 278 (81.5) & \\
\hline
\end{tabular}

\section{Discussion}

The data obtained from this cross sectional study revealed an overall prevalence of DM of $12.3 \%$ in Jazan Region. This estimate is far less than what has been reported by previous studies in KSA [8] [9] which produced prevalence rate of $23.7 \%$ and $23.1 \%$ respectively. This is may be attributed to the size of the study. Also the study showed that the prevalence of DM in female is higher than male, along the lines of some international studies [10] [11], only justification may be the unequal sex ratio of male in female participated in the survey. The study further showed increase of prevalence of DM with age. The increase in the prevalence of diabetes mellitus with age is expected and has been observed in all studies reported elsewhere. However, the increase in prevalence in those above aged 60 years and above was very significant. This trend is noticed in other studies in other parts of KSA and other countries characterized by high prevalence of DM [8]-[12].

The univariate analyses showed a significant association between BMI and DM, BMI greater than 30 increases the risk of DM twice. The relationship between diabetes mellitus and obesity is well established and has been documented in many other surveys, nationally and internationally [9]-[13]. International study involved 49 developing countries documented that overweight (BMI) and obese (BMI $>30 \mathrm{~kg} / \mathrm{m}^{2}$ ) were significantly associated with odds of having diabetes as compared with those who were of normal weight [14].

The study did not find an independent relationship between diabetes and Khat chewing, the habit is highly prevalent among Jazan population. In fact no previous studies in KSA investigated the relationship between Khat chewing and DM. DM is associated with family history of diabetes. The DM prevalence is higher and related independently $(\mathrm{OR}=3.2)$ among people with diabetes history in their families. This association is found to 
be higher in surveys conducted elsewhere [11] [15] [16].

The study further documented an association between diabetes and physical activity. The group with physical activity had the lowest prevalence of DM. Physical activity level might affect prevalence through its relationship with other factors such as obesity and hypertension [17].

The study revealed high level of knowledge about important of monitoring DM among studied population, with no significant difference between males and females. These findings may be along the same line of other studies in KSA which produced good level of Knowledge about DM [18].

Several limitations should be taken into consideration when interpreting the results of the present study. (1) The present analysis is based on cross sectional data therefore; the associations of diabetes with other independent variables should be interpreted with causation. (2) The distribution of study participants according to gender was biased towards male and this may affected the estimated prevalence of DM for this study and this may explain the that why prevalence of the DM among male was far less than the national level.

\section{Conclusion}

In conclusion, this cross sectional study showed that the prevalence of DM in Jazan region is $12.3 \%$. Increased prevalence of diabetes calls for urgent steps towards prevention and health promotion, programs designed to reduce its burden. Knowledge of the patients regarding complications of DM is necessary and important for management of the disease.

\section{Acknowledgements}

The author would like to acknowledge with much appreciation the assistance provided by Jazan Directorate of Health, KSA. Thanks also extend to the students and all study participants who sacrificed their valuable time taking active part of the survey.

\section{References}

[1] Amos, A.F., McCarty, D.J. and Zimmet, P. (1997) The Rising Global Burden of Diabetes and Its Complications: Estimates and Projections to the Year 2010. Diabetic Medicine, 14, S7-S85. http://dx.doi.org/10.1002/(sici)1096-9136(199712)14:5+<s7::aid-dia522>3.3.co;2-i

[2] Wild, S., Roglic, G., Green, A., Sicree, R. and King, H. (2004) Global Prevalence of Diabetes: Estimates for the Year 2000 and Projections for 2030. Diabetes Care, 27, 1047-1053. http://dx.doi.org/10.2337/diacare.27.5.1047

[3] Al-Nozha, M.M., Arafah, M.R., Al-Mazrou, Y.Y., Al-Maatouq, M.A., Khan, N.B., Khalil, M.Z., Al-Khadra, A.H., Al-Marzouki, K., Abdullah, M.A., Al-Harthi, S.S., Al-Shahid, M.S., Nouh, M.S. and Al-Mobeireek, A. (2004) Coronary Artery Disease in Saudi Arabia. Saudi Medical Journal, 25, 1165-1171.

[4] Al-Hazzaa, H.M. (2002) Physical Activity, Fitness and Fatness among Saudi Children and Adolescents: Implications for Cardiovascular Health. Saudi Medical Journal, 23, 144-150.

[5] Alwan, A. (1997) Noncommunicable Diseases a Major Challenge to Public Health in the Region. Eastern Mediterranean Health Journal, 3, 6-16.

[6] Saadia, Z., Rushdi, S., Alsheha, M., Saeed, H. and Rajab, M. (2010) A Study of Knowledge Attitude And Practices Of Saudi Women Towards Diabetes Mellitus. A (KAP) Study in Al-Qassim Region. The Internet Journal of Health, 11, Number 2. http://dx.doi.org/10.5580/1d29

[7] Angeles-Llerenas, A., Carbajal-Sánchez, N., Allen, B., Zamora-Muñoz, S. and Lazcano-Ponce, E. (2005) Gender, Body Mass Index and Sociodemographic Variables Associated with Knowledge about Type 2 Diabetes Mellitus among 13,293 Mexican Students. Acta Diabetologica, 42, 36-45. http://dx.doi.org/10.1007/s00592-005-0172-4

[8] Al-Nozha, M.M., Al-Maatouq, M.A., Al-Mazrou, Y.Y., Al-Harthi, S.S., Arafah, M.R., Khalil, M.Z., Khan, N.B., Al-Khadra, A., Al-Marzouki, K., Nouh, M.S., Abdullah, M., Attas, O., Al-Shahid, M.S. and Al-Mobeireek, A. (2004) Diabetes Mellitus in Saudi Arabia. Saudi Medical Journal, 25, 1603-1610.

[9] Al-Daghri, N.M. (2011) Diabetes Mellitus Type 2 and Other Chronic Non-Communicable Diseases in the Central Region, Saudi Arabia (Riyadh Cohort 2): A Decade of an Epidemic. BMC Medicine, 9, 76-81. http://dx.doi.org/10.1186/1741-7015-9-76

[10] Kelestimur, F., Cetin, M., Pasaoglu, H., et al. (1999) The Prevalence and Identification of Risk Factors for Type 2 Diabetes Mellitus and Impaired Glucose Tolerance in Kayseri, Central Anatolia, Turkey. Acta Diabetologica, 36, 85-91. http://dx.doi.org/10.1007/s005920050150 
[11] Nyenwe, E.A., Odia, O.J., Ihekwaba, A.E., et al. (2003) Type 2 Diabetes in Adult Nigerian’s: A Study of Its Prevalence and Risk Factors in Port Harcourt, Nigeria. Diabetes Research and Clinical Practice, 62, 177-185. http://dx.doi.org/10.1016/j.diabres.2003.07.002

[12] Fatani, H.H., Mira, S.A. and El-Zubier, A.G. (1987) Prevalence of Diabetes Mellitus in Rural Saudi Arabia. Diabetes Care, 10, 180-183.

[13] International Diabetes Federation. Diabetes Prevalence, 2005. http://www.idf.org/home/index.cfm?node=264

[14] Liu, L., Yin, X., et al. (2012) Global Variability in Diabetes Mellitus and Its Association with Body Weight and Primary Healthcare Support in 49 Low- and Middle-Income Developing Countries. Diabetic Medicine, 29, 995-1002. http://dx.doi.org/10.1111/j.1464-5491.2011.03549.x

[15] Fletcher, B., Gulanick, M. and Lamendola, C. (2002) Risk Factors for Type 2 Diabetes Mellitus. The Journal of Cardiovascular Nursing, 16, 17-23.

[16] Van der Sande, M.A.B., Walraven, G.E.L., Milligan, P.J.M., et al. (2001) Family History: An Opportunity for Early Interventions and Improved Control of Hypertension, Obesity and Diabetes. Bulletin of the World Health Organization, 79, 321-328.

[17] Aksu, H., Pala, K. and Aksu, H. (2006) Prevalence and Associated Risk Factors of Type 2 Diabetes Mellitus in Nilufer District, Bursa, Turkey. International Journal of Diabetes and Metabolism, 14, 98-102.

[18] Mohieldein, A.H., Al Zohairy, M.A., et al. (2011) Awareness of Diabetes Mellitus among Saudi Non-Diabetic Population in Al-Qassim Region, Saudi Arabia. Journal of Diabetes and Endocrinology, 2, 14-19. 